\title{
Rose-Myriam Réjouis, Veillées pour les mots
}

\section{Francesca Torchi}

\section{(2) OpenEdition}

\section{Journals}

\section{Edizione digitale}

URL: http://journals.openedition.org/studifrancesi/30906

DOI: 10.4000/studifrancesi.30906

ISSN: 2421-5856

\section{Editore}

Rosenberg \& Sellier

\section{Edizione cartacea}

Data di pubblicazione: 1 avril 2006

Paginazione: 201-202

ISSN: 0039-2944

\section{Notizia bibliografica digitale}

Francesca Torchi, «Rose-Myriam Réjouis, Veillées pour les mots», Studi Francesi [Online], 148 (XLX | I) | 2006, online dal 30 novembre 2015, consultato il 22 avril 2021. URL: http://journals.openedition.org/ studifrancesi/30906 ; DOI: https://doi.org/10.4000/studifrancesi.30906

\section{Questo documento è stato generato automaticamente il 22 avril 2021.}

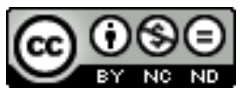

Studi Francesi è distribuita con Licenza Creative Commons Attribuzione - Non commerciale - Non opere derivate 4.0 Internazionale. 


\title{
Rose-Myriam Réjouis, Veillées pour les mots
}

\author{
Francesca Torchi
}

\section{NOTIZIA}

ROSE-MYRIAM RÉJOUIS, Veillées pour les mots, Paris, Karthala, 2004, pp. 129.

1 Il titolo di questo saggio sulla letteratura delle Antille francofone gioca sulla vicinanza fonetica e grafica delle parole mot e mort ed evoca subito alcuni elementi della cultura caraibica come la veglia funebre, uno dei luoghi privilegiati del racconto orale. La veglia di cui il testo si occupa è però, questa volta, per le parole. Se da un lato, dunque, l'autrice accenna all'impegno degli scrittori delle Antille francesi nel recupero di una parola orale e originaria e nello stesso tempo di inventare un linguaggio letterario proprio e originale, dall'altro evoca anche la morte come situazione e tema ricorrente. Ed in effetti, le tre analisi che costituiscono le sezioni in cui l'intero saggio è suddiviso sono dedicate al tema della morte dell'eroe e alle funzioni narrative che può svolgere. Attraverso l'osservazione di questo tema in Et les chiens se taisaient di Aimé Césaire, Solibo Magnifique di Patrick Chamoiseau e Traversée de la mangrove di Maryse Condé, l'autrice ribadisce la fondamentale ricerca di questi autori sulla scrittura e sul ruolo dello scrittore. Al tempo stesso è nelle sue intenzioni offrire una lettura di questi tre testi finalizzata a mettere in luce una genealogia letteraria che li unisca e renda, pur nella differenza, le ricerche di Césaire, Chamoiseau e Condé parti coerenti di un discorso letterario specificamente antillese.

2 La pièce di Césaire mette in scena un eroe martire, il Rebelle, che vorrebbe porsi come un esempio per il proprio popolo, per la propria collettività di riferimento, ma che non viene compreso, e sceglie infine di morire come martire in un sacrificio vano. L'assenza di destinatario consapevole rende il dialogo con il suo interlocutore un monologo con il lettore, unico pubblico possibile. Strozzato dalle sue stesse parole mentre sta raccontando, anche l'eroe di Chamoiseau, il conteur créole Solibo Magnifique, muore di 
fronte ad un pubblico che lo ascolta ma che non lo comprende più. I suoi racconti, eredità di un passato prima africano e poi specificamente caraibico, sono ormai recepiti solo come un vuoto rituale. La morte, tuttavia, non rappresenta l'epilogo del romanzo ma il suo punto iniziale. È proprio da questa incomprensione infatti che il testo nasce. Come se Chamoiseau, sia da un punto di vista tematico che stilistico, rispondesse a Césaire con la propria visione di ciò che può accadere dopo la morte dell'eroe: la pièce diventa un romanzo in cui risuonano le dinamiche teatrali del conte créole, e la morte dell'eroe permette a Chamoiseau di dare corpo allo scrittore come personaggio, che drammatizza la ricerca sulla parola orale e letteraria. Anche per Condé, che sta a sua volta 'rispondendo' a Chamoiseau, la morte dell'eroe corrisponde all'inizio del romanzo. Lo scrittore che Condé mette in scena è il morto, e la sua figura si eclissa nelle voci che compongono la collettività della Guadalupa. Il suo è uno scrittore in esilio, che con la sua assenza o distanza può dar voce all'identità collettiva che osserva dall'esterno.

Rose-Myriam Réjouis fa discendere da Césaire le riflessioni di Chamoiseau e di Condé: Césaire ha fatto morire un eroe e loro partono da quella morte per dar voce all'identità dell'interlocutore dell'eroe. Come nella veillée, nella letteratura antillese, la morte corrisponde alla nascita e alla riscoperta della parola, al recupero dell'identità di una collettività alla ricerca della propria identità. 